\title{
A "Saga do Cavalo Pantaneiro" e a pecuária na região de Corumbá, MS, como tema da Escola de Samba Mocidade Independente de Nova Corumbá
}

\author{
The "Saga of the Pantanal Horse" and livestock in the region of Corumbá, MS, as the \\ theme of the Escola de Samba Mocidade Independente de Nova Corumbá
La "Saga du Pantanal Cheval" et bétail dans la région de Corumbá, MS, comme le thème de la Escola de Samba Mocidade Independente de Nova Corumbá

\section{La "Saga del caballo del Pantanal" y de la ganadería en la región de Corumbá, MS, como el tema de la Escola de Samba Mocidade Independente de Nova Corumbá}

\author{
Denise Abrão Nachif* \\ (denisenachif10@gmail.com) \\ Gilberto Luiz Alves* \\ (gilbertoalves9@uol.com.br)
}

Recebido em 03/08/2015; revisado e aprovado em 07/10/2015; aceito em 20/11/2015

DOI: http://dx.doi.org/10.20435/1984042X2016214

\begin{abstract}
Resumo: Este artigo articula aspectos da História e sua representação em manifestações culturais populares, com foco na história de Corumbá, região de Mato Grosso do Sul. Para tanto, traz um breve histórico da ocupação, colonização, desenvolvimento e da região, à luz de contribuições de Proença (1992a; 1992b), Alves (2004), Fernandes (2009) e Dias (2009), entre outros autores. O foco recai sobre a pecuária e o cavalo pantaneiro, tema e personagem sobre os quais se pronuncia a Escola de Samba Mocidade Independente de Nova Corumbá, desenvolvendo o enredo "Saga do Cavalo Pantaneiro".

Palavras-chave: desenvolvimento regional; cavalo pantaneiro; carnaval de Corumbá.
\end{abstract}

Abstract: This article articulates aspects of History and its representation in popular cultural events, with a focus on history of Corumbá, Mato Grosso do Sul region. To do this, get a brief history of the occupation, colonization, and development of the region, in the light of contributions of Proença (1992a; 1992b), Alves (2004), Fernandes (2009) and Dias (2009), among other authors. The focus falls on the livestock and the Pantanal horse, theme and character about which pronounced the Samba School Mocidade Independente de Nova Corumbá, developing the plot "Saga of the Pantanal Horse".

Key words: regional development; pantanal horse; carnival of Corumbá.

Résumé: Cet article décrit les aspects de l'histoire et de sa représentation à des manifestations culturelles populaires, en mettant l'accent sur l'histoire de Corumbá, Mato Grosso Sul région. Pour ce faire, obtenir une brève histoire de l'occupation, la colonisation et le développement de la région, à la lumière des contributions de Proença (1992 a, 1992 b), Alves (2004), Fernandes (2009) et Dias (2009), parmi les autres auteurs. L'accent tombe sur le bétail et le Pantanal cheval, thème et personnage qui prononce la Samba École Mocidade Independente de Nouveau Corumbá, développer l'intrigue de « La Saga du Cheval Pantanal ».

Mots-clés: developpement regional; cheval pantanal; carnaval de Corumbá.

Resumen: Este artículo articula aspectos de la Historia y su representación en eventos culturales populares, con énfasis en historia de Corumbá, Mato Grosso do Sul región. Para ello, haz una breve historia de la ocupación, colonización y desarrollo de la región, teniendo en cuenta las contribuciones de Proença (1992a; 1992b), Alves (2004), Fernandes (2009) y Días (2009), entre otros autores. El enfoque cae sobre el ganado y el caballo de Pantanal, tema y personaje que pronuncia la Samba la Escuela Mocidade Independente de Nuevo Corumbá, desarrollo de la trama de la «Saga de los Caballos del Pantanal».

Palabras clave: desarrollo regional; pantanal caballo; carnaval de Corumbá.

\section{INTRODUÇÃO}

Essa reflexão conduz-se para a importância histórica do cavalo pantaneiro para o desenvolvimento pecuário da região de Corumbá, Mato Grosso do Sul, consagrada na festa popular carnaval do ano 2014 no desfile da Escola de Samba Mocidade Independente de Nova Corumbá.
Dessa forma, a Escola representou na avenida do samba a história do surgimento do cavalo pantaneiro e o desenvolvimento da pecuária e região do Pantanal.

A apreensão com o caráter econômico das festas populares nacionais, muitas vezes movidas pela indústria cultural, e em especial o carnaval de Corumbá, permite-nos questionar sobre a ressignificação da história

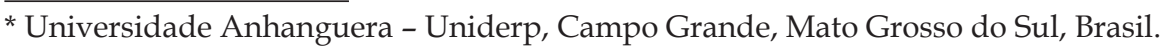


oferecida pelos agentes culturais na celebração de seus valores, não analisando realidades e aceitando de forma narcotizada a realidade social (SOUZA, 2004).

Esse fato, objetivando este estudo, nos leva a refletir como a Escola de Samba Mocidade Independente de Nova Corumbá mantém em si a consciência social e percepção sensorial da ocupação e desenvolvimento da região de Corumbá, apresentada na passarela do samba.

A tática metodológica empregada nesta pesquisa constituiu-se por documentos dos setores públicos, projetos e jornais, livros e artigos.

Por meio de narrativas e relatos de memórias dos gestores públicos, festeiros, público e participantes, deu-se a expressão dos valores da sociedade corumbaense.

Observar e analisar o desfile da Escola de Samba Mocidade Independente de Nova Corumbá, para registro de imagens e filmes, foi fundamental para a sustentação da análise. Quanto ao delineamento da pesquisa, buscou-se contextualizar aspectos da história da ocupação da região de Corumbá que apontam para a chegada das expedições espanholas, com grande número de indígenas que domaram o cavalo pantaneiro, no intuito de o utilizar para o desenvolvimento pecuário da região do Pantanal, até a Fundação de Corumbá.

Nesse contexto, descreve-se o desfile da Escola de Samba Mocidade Independente de Nova Corumbá, no carnaval de Corumbá, que celebrou a história da sua região.

\section{ASPECTOS DA HISTÓRIA DA OCUPAÇÃO DE CORUMBÁ}

Na defesa do território da fronteira Brasil-Bolívia, para protegê-lo da exploração de minas e prata, ocorreram, desde o século XVI até o XVIII, disputas entre espanhóis e portugueses, iniciando-se, assim, o processo de ocupação da Planície Pantaneira.

Ressalta-se que as expedições espanholas contavam com grande número de indígenas, que viajavam em canoas e percorriam os campos de vacarias utilizando cavalos. Durante essas expedições, povoados foram constituídos, e o número de jesuítas, reduzido (PROENÇA, 1992a). Diante desse panorama, houve um alargamento cultural, decorrente da conexão entre a sociedade europeia e a indígena, que resultou em uma importante contribuição para uma nova cultura. Enquanto os indígenas tinham o conhecimento do ambiente, caminhos abertos, "domesticação" das plantas nativas e técnicas de trabalho com fibras vegetais, os europeus dominavam a fabricação de armas e de artesanatos desenvolvidos, o uso de roda e do arado, a domesticação de animais e a produção de diversos alimentos (FERNANDES, 2009).

Sobre os povos indígenas, Proença (1992a, p. 24) registra:

Os índios assim chamados erronea-
mente pelos europeus, os quais
imaginavam ter alcançado as sonha-
das terras das Índias pela rota do
Ocidente, iniciaram a história da
ocupação humana no Pantanal, onde
viveram, durante séculos, uma vida
errante e livre. Foram os senhores da
terra, na qual se adaptaram ao longo
dos rios ou nas serras circundantes,
formando grupos tribais e linguísti-
cos, cada qual com seus costumes,
vangloriando-se das boas qualidades
de caçados num mundo cheio de
pássaros e outros bichos.
Os rios, além delhes fornecerem o ali-
mento, facultavam-lhes o transporte.
Os campos abertos propiciavam-lhes
uma infinidade de animais cujos
rastros seguiam com seus cavalos ou
a pé, dando-nos a impressão de que
não fora por acaso que se estabele-
ceram no imenso território. Foram
eles, os índios [...] que tiveram papel
fundamental na formação história e
territorial da então esquecida Pro-
víncia, abrindo picadas, ensinando
os caminhos aos civilizados, com os
quais algumas tribos mantiveram
contato pacífico, subjugando-se a
eles como bestas de carga, servindo
de instrumentos às ambições de con-
quista, submetendo-se a uma triste e
vergonhosa escravidão.

A ocupação do Pantanal por outros povos teve início somente após a metade do século XVIII, sendo a resistência dos povos indígenas e as condições adversas do ambiente os fatores responsáveis por tal ocupação tardia. Afora os bandeirantes vindos de São Paulo, o mercantilismo português teve 
importante participação no povoamento da região, em decorrência da mineração de ouro, criando um povoamento, que daria espaço a futuras cidades, e fortificações militares, com o poder direcionado à metrópole portuguesa (SOUZA, s.d.).

Apesar de a cultura e a identidade dos indígenas terem sido fortemente atacadas pelos missionários, resultando na redução da população indígena, surgiu uma nova sociedade, oriunda da interação entre brancos e indígenas (FERNANDES, 2009).

Antes do surgimento da cidade de Corumbá, mais especificamente em 1775, foi construído o Forte Coimbra, tornando-se, junto com a vila, ponto estratégico para bloquear o avanço de espanhóis e índios paiaguás e guaicurus. Dessa forma, em 21 de setembro de 1778, foi fundada a cidade de Corumbá, sob o mando do Capitão General Luis Albuquerque de Mello Pereira e Cáceres (DIAS, 2009).

\subsection{Desenvolvimento regional e pecuária}

De acordo com Proença (1992a, p. 55)

Terminada a fase de consolidação de fronteiras, construídos os povoados, fundados os fortes, feitas as manobras para apagar a chama guerreira dos índios Paiaguás e ainda devido a decadência das lavras auríferas que facilmente se exauriam, era necessário incrementar uma outra atividade econômica na imensa planície pantaneira. Para isso, 4 elementos foram fundamentais: o desbravador-pioneiro, o vaqueiro, o cavalo e o boi.

No que diz respeito ao cavalo, sua história é caracterizada por dois momentos, dos quais o primeiro é relatado por Dr. Luiz Otávio Carneiro, em entrevista a Geraldo Albaneze (2014).

"Cabeza de Vaca", Dom Alvaro Nuñes, com a missão de salvar Buenos Aires, destruída por índios, e desenvolver Assunção, no Paraguai, chegou a Santa Catarina com quatrocentas pessoas e somente 26 cavalos. Foi deixando suas marcas durante a travessia do Pantanal, entre os rios Cuiabá e Paraguai. Durante o período de fundação de Buenos Aires, em decorrência do incêndio da vila e seu povoamento, cavalos e éguas foram abandonados. Além de reaprenderem a viver no mato, esses animais reproduziram-se de tal forma que, em 1580, já havia registro de manadas selvagens nas planícies argentinas e, após um século, milhares de cavalos chegaram ao Paraguai e, posteriormente, ao Brasil, trazidos pelas mãos dos índios cavaleiros.

O segundo momento diz respeito ao cavalo vindo da Europa, que assombrou os índios, pois a maioria das tribos tinham-no ou como fera, evitando-o, ou como caça, transformando-o em comida. Somente uma nação, a dos embaías-guaicurus, entendeu que o cavalo serviria como transporte e arma. Como esses índios, senhoriais e conquistadores, usaram o cavalo para aumentar infinitamente sua capacidade de luta e raio de ação, transformando-se, então, nos "índios cavaleiros"?

De acordo com depoimento de Carneiro (2014), em 1795, o Coronel Rodrigues Prado, comandante do Forte Coimbra, relatou que 8 mil dos animais que compunham o rebanho eram dos índios cavaleiros, que, em sua grande maioria, eram mansos e adestrados na arte da guerra, da cavalaria e do esporte.

Ao iniciar-se a guerra, em 1864, os índios cavaleiros lutaram ao lado dos brasileiros, num regimento pantaneiro formado com cavalos de sua própria criação, fator importante para a defesa de Mato Grosso. A Guerra do Paraguai estendeu-se por dois anos e provocou uma das maiores crises: a região sofreu grande desorganização política e administrativa, resultando em um retrocesso na vida social e forte abalo na economia, decorrentes da suspensão da navegação fluvial internacional (PROENÇA, 1992a).

Após o término da guerra, a cidade começaria a progredir, retomando o comércio fluvial, e a chegada de imigrantes europeus, que assumiram atividades comerciais, além de trabalhadores latino-americanos, fortaleceriam a economia local. Após a construção da Estrada de Ferro Noroeste do Brasil, houve, no entanto, uma mudança de eixo econômico para Campo Grande, gerando, novamente, um retrocesso na economia local. A ferrovia veio substituir o transporte fluvial, cujo objetivo era integrar o mercado paulista ao Porto de Santos. Era a decadência do transporte fluvial.

Com a desativação das atividades portuárias relacionadas ao comércio e atividades 
econômicas, Corumbá encontraria forças na atividade pecuária, já que as condições naturais favoreciam a formação de uma boa pastagem e a ferrovia facilitava o escoamento da produção (DIAS, 2009).

Segundo Souza (s.d., p. 87)

A pecuária, a partir do final da guerra do Paraguai, tomara um impulso vigoroso, refazendo-se inteiramente e progredindo auspiciosamente, de modo a transformar o município no mais importante reduto criatório do Estado. As fazendas, em pleno florescimento, depois de assoladas pelos invasores, espalhavam-se promissoras pelas zonas de Nhecolândia, Paiaguás, Nabileque e na margem direita do Paraguai, com uma produção cada vez maior.

Nhecolândia é uma das regiões mais importantes na pecuária do Pantanal, abrangendo o município de Corumbá, limitado pelos rios Paraguai, Negro, Taquari, e bordas do planalto de Maracaju, na região de Rio Verde, a leste (BARROS, 1998). Embora possua características gerais comuns a outros pantanais, essa região tem suas próprias salinas, lagoas, baías, campos-limpos, capões (bosques), cordilheiras, cerrados, corixos e vazantes, distribuídos harmonicamente (PROENÇA, 1992b).

$\mathrm{O}$ autor relata que

Apesar de inundado o terreno permanece firme. E é nessa firmeza que o cavalo pantaneiro encontra apoio para carregar o homem aos mais distantes lugares, batendo os cascos no viço das gramíneas num chape-chape resistente e vagaroso, sem se preocupar com os peixes que lhe cruzam as patas, como se caminhassem - cavalo e homem - num natural aquário sobre o qual os raios de sol insistem em lhe dar exuberância. É verdade que, em certos trechos [...] o terreno se amolece, principalmente no chamado baixo Pantanal. Aí, sem mais nem menos esbarramos num brejo [...] que nos obriga a parar de repente e ficar sentindo o entardecer revoado de pássaros, o silêncio chegando da vastidão perdida, o gorgulho da lama preta, amolecida, intercalando-se com o coaxar dos sapos. (PROENÇA, 1992, p. 13).
Segundo Alves (2012), coube a Joaquim Eugênio, Nheco, a recolonização da área herdada de seu pai, Barão de Vila Maria. Com a ajuda de familiares, recuperaria edificações arruinadas bem como construiria outras, além de reintroduzir o gado no campo.

Proença (1992b, p. 99) relata que, ao convidar seus familiares, Nheco dizia que "Poderiam levar tudo: família, gado, animais; possuía mais de cem léguas de terra e eles poderiam escolher a área que mais lhes conviesse. Faria doação, ajudaria na condução das reses, arcaria com as despesas da mudança."

Assim, a região de Nhecolândia é o resultado da união de criadores de gado aparentados com ações para superar a pobreza do final do século XIX, causada pela Guerra do Paraguai, havendo a mobilização de forças para o desbravamento dessa área. Nesse momento, entrariam em ação pioneiros recém-chegados, aptos para tal trabalho (ALVES, 2004).

A pecuária fortaleceu-se de tal forma, que, segundo Barros (1998, p. 99),

Na última década do século passado, conta-nos José de Barros Maciel, o Nheco possuía 3.000 cabeças de gado. Ao morrer, em 1909, andava em torno de 15.000. Menos de três décadas depois seus herdeiros e sucessores, nas mesmas terras, contavam em torno de 100.000 reses. Em 1934 Carlos Vandoni de Barros, em um trabalho sobre a Nhecolândia, avaliou, em toda a zona, 500.000 bovinos. $\mathrm{Na}$ metade do século já ultrapassariam um milhão de cabeças. Nessa época, o boi já tinha domado a macega bruta e desenhado o mapa da Nhecolândia.

O sucesso da ação rendeu a Nheco uma homenagem: a denominação dessa região como Nhecolândia. E essa ação foi primordial para o desenvolvimento e ocupação da cidade de Corumbá, encontrando-se enraizada na memória afetiva de seus habitantes. Parte de uma história que serve de motivo para celebrações atuais por meio de movimentos culturais.

\section{CULTURA E CARNAVAL DE CORUMBÁ}

A cultura atribui uma produção a serviço das manifestações do homem, estabelecendo-se pela criação intelectual e artística, como 
resultado do aprimoramento de seus valores, e refletindo-se em todos os seus aspectos. Assim, a cultura é proposta, de forma inicial, como um conjunto de práticas provenientes da vida social e que tem a função de organizá-la e de dar-lhe sentido (BARBOSA, 2004).

Assim, o termo cultura consiste em ações, proporcionando estímulos, atrações e sedução, ajustando constantes mudanças e valores, atestando uma sociedade.

Do desenvolvimento e transformação cultural de Corumbá, na década de 1970 em diante, iniciou-se um processo de desmonte do parque industrial existente na cidade, decorrente da introdução da estrada de ferro, que paralisou a frágil economia local, elevando a importância da relação do capital com atividades terciárias, como o turismo, serviços e festas populares assim como o carnaval.

A festa popular carnaval, oriunda das celebrações dionisíacas nas ruas de Roma, nos séculos VII e VI a.C., apresentava em sua exuberância um carro com grande tonel de vinho, que, distribuído em abundância ao povo, causava grandes euforias (BARBOSA, 2004). Desse princípio, a festa prosperou como contraponto a um cotidiano marcado pelo trabalho duro e pela sucessão de proibições e de experiências desagradáveis, entre elas os conflitos hierárquicos.

Desde a experiência dos povos egípcios de festas da colheita ate as celebrações cristãs que antecediam as penitências da Quaresma, a festa, desfigurando o real, numa tentativa de satirizar as convenções religiosas, sociais e políticas, se apresentava como uma festa pagã de adeus à carne (carne-vale), celebrando com fartura as carnes e bebidas, a dança sem limites, o sexo, e o desejo de beleza (ARAUJO, 2003).

$O$ festejo carnaval empregada como sucesso desde o século XIV, evoluiu com caráter libertino no ocidente a partir do século XVIII. As celebradas em culturas andinas e pós-coloniais, como sendo uma evolução a partir das festas religiosas, mantém em si um composto híbrido cultural (CANCLINI, 2011).

Nessa perspectiva, os padrões de comportamento herdados das festas populares dos ciclos litúrgicos, apresentam padrões de consumo durante o festejo, não apenas comidas e bebidas, mas também artigos, fruto da revolução industrial para atender às exigências da divisão do trabalho (SOUZA, 2004).
Queiroz (1973), quando se refere a festas populares, menciona que o homem expõe valores sociais de forma adaptativa para contar uma história, estabelecendo articulação direta entre o passado e presente, celebrando a sua memória.

Na celebração brasileira, o carnaval constituiu-se pelo seguinte:

A implantação no Brasil ocorreu desde os primeiros tempos da colonização portuguesa com sucesso indiscutível; sua celebração data de pelo menos três séculos, sempre com igual entusiasmo. É citado em documentos que datam de 1605, com o mesmo nome que trouxera de Portugal - Entrudo - que significaria, ao que parece, "entrada". Enquanto na Europa e na América Ibérica o carnaval se associava a determinadas regiões e mesmo a algumas pequenas aglomerações urbanas, no Brasil sempre foi encontrado em todos os povoados e cidades. Seu sucesso crescente tornou-o uma das imagens marcantes nacionais: "pais do carnaval" é um dos atributos que o povo se orgulha. As comemorações são encontradas por toda parte e com o mesmo programa, as variações sendo mínimas: desfiles de escolas de samba, bailes, pequenos grupos de sujos cantando e dançando pelas esquinas constituem o programa habitual. (QUEIROZ, 1999, p. 12).

Da forma festiva brasileira, emerge a necessidade de verificar na literatura o carnaval de Corumbá, que, para alguns estudiosos, deve ser concebido como um fenômeno de potencial crítico e tradicional, pois, sendo uma festa local, reproduz, em seus espaços, os traços da formação histórica da cidade (SANTOS, 1996).

Em Corumbá, a festa ocorre desde o início do século XIX e tem contado com a presença de escolas de samba, blocos e cordões, além dos bailes e atrações musicais. Até a metade do século XIX, era uma manifestação espontânea da sociedade e, a partir de então, passou a ser gerenciada pelo governo municipal, com apoio do governo estadual e do governo federal.

Proença (1992a) relata que a primeira escola de samba, denominada "Deixa Falar", foi apresentada em Corumbá por marinheiros 
de Ladário procedentes do Rio de Janeiro, trazendo o ritmo, a cadência e a ginga cariocas.

Até a década de 1990, o festejo conviveu com dificuldades econômico-financeiras, crises sucessivas, tropeços, desavenças, porém buscando transformar essas adversidades em críticas inteligentes ou oportunidades (PROENÇA, 1992a, p. 87).

A festa popular "Carnaval", reflexo de valores sociais, marcou, desde os primórdios da história, a vida religiosa e política das populações, sendo celebrada ainda hoje com espetáculos teatrais na passarela, num ato performático. Atualmente, com a transformação da sociedade moderna, o carnaval corumbaense reproduz excessivo consumo, movido pela indústria e por agentes sociais que movimentam todo o setor. Em outras esferas, alguns grupos formados pelas escolas de samba mantêm, todavia, seu caráter ideológico e, em seus desfiles, os valores históricos e sociais são celebrados.

\subsection{Escola de Samba Mocidade Independente de Nova Corumbá}

A Escola de Samba Mocidade Independente da Nova Corumbá é uma instituição recreativa, fundada em 22 de junho de 1999 por Fernanda Vanucci. Atualmente, o presidente da escola é Alfredo Sartory, e o vice-presidente, Luiz Bosco Delgado; Waldir Staut Albaneze, Renato dos Santos e João Marques são os diretores e Geraldo Albaneze é diretor de carnaval (ALBANEZE, 2014).

Buscando celebrar a história da região, a escola teve como tema, no carnaval de 2006, "Nova Corumbá, do sonho à realidade, centro do esporte, cultura e lazer"; em 2008, "Entre luz, cores e fantasias, brilha uma estrela no céu da mocidade, Parabéns Corumbá 230 anos"; "Nas águas do Paraguai, nasce um rio de esperança" foi o tema em 2010; em 2012, "Nos trilhos da folia, a Mocidade apresenta: Mato Grosso do Sul, um Santuário de cor e alegria" em 2012. Na celebração do desfile do ano 2015, a escola fez jus ao seu ideário, apresentando na avenida uma homenagem à marinha do Brasil, com o tema "Lançou a âncora, fixou raízes: a Marinha do Brasil, uma epopeia no Pantanal", evidenciando a história da navegação e a presença do $6^{\circ}$ Distrito Naval no Pantanal. Reforçava, pois, a história local como traço marcante da sua cultura e tradição.

No ano de 2014, classificando-se no desfile em terceiro lugar, com 178,1 pontos, e mantendo-se no primeiro grupo das escolas de samba de Corumbá, a escola ofereceu ao público "A saga do Cavalo Pantaneiro", que é o objeto de estudo deste artigo.

Albaneze (2014) relata que o enredo escolhido veio contar, com base na versão apresentada, em entrevista, pelo Dr. Luiz Otávio Carneiro, o surgimento do cavalo pantaneiro na região do Pantanal, bem como o desbravamento da Nhecolândia e a sua viagem denominada de "Cavalgando pelo Pantanal, rota pioneira":

É o enredo que presta uma homenagem ao animal que ajudou a desenvolver a região do Pantanal e graças a ele o povoamento dessa região, surgindo uma paixão e uma relação muito grande entre o cavalo, o índio Guaicuru e o homem pantaneiro.

O desfile da escola de samba, presenciado pela pesquisadora, apresentou o enredo "Um galope de amor", autoria de Marcos César e Geraldo Albaneze, celebrando o movimento da ocupação local bem como a importância do cavalo pantaneiro para a região. A letra do samba-enredo descreve de forma poética e resumida tal acontecimento:
Canta Mocidade!
Na passarela, um galope de amor, Cruzando meu Pantanal, adrenali- na no ar,
A minha arara, vai voar!
Por terra e égua a cavalgar
Trilhando a história do cavalo
pantaneiro
Com Zap, seu melhor amigo,
Luiz Otávio Carneiro,
Com el Cabeza de Vaca!
O cavalo chegou
Índio valente Guaicuru
O domesticou
Em verde, vermelho e branco,
Corre, corre, Guaicuru tropeiro
Swinga, minha bateria,
O show é seu, cavalo pantaneiro!
De Poconé à Corumbá
Aventura, emoção!
Os encantos deste chão.
De Nheco à Nhecolândia 
O paraíso contagia, Confiança, resistência, Força, raça e magia.

Durante o desfile, a criatividade visual, a composição coreográfica, a musicalidade, e os recursos humanos contribuíram de maneira significativa para abrilhantar a história contada na passarela do samba na madrugada do dia 4 de março de 2014, na avenida General Rondon, centro da cidade de Corumbá.

Com cinco carros alegóricos: carro Abre-Alas, carro da Espanha, carro Índio Guaicuru e Pantanal, carro da Nhecolândia e os Cavalos, e carro Costumes Pantaneiros, somados aos seus 1.200 componentes, distribuídos numa dança coletiva, organizada em
14 alas, expressou-se, do seguinte modo, a história das relações sociais locais:

O primeiro setor do desfile - "Espanha" - deu ênfase à tradição espanhola, narrando o momento em que o cavalo pantaneiro chegou ao Pantanal com o nobre Espanhol “El Cabeza de Vaca", em 1548, deparando a lenda de que toda a região era formada por um mar. Apresentação aparente como produto cênico na Comissão de Frente e Segunda Ala.

No setor seguinte, o carro alegórico Abre-Alas (figura 1), trazendo a escultura de uma arara, fez alusão ao voo da ave ao acompanhar Nheco Gomes da Silva, no lombo do cavalo pantaneiro, na trajetória de Poconé a Corumbá.

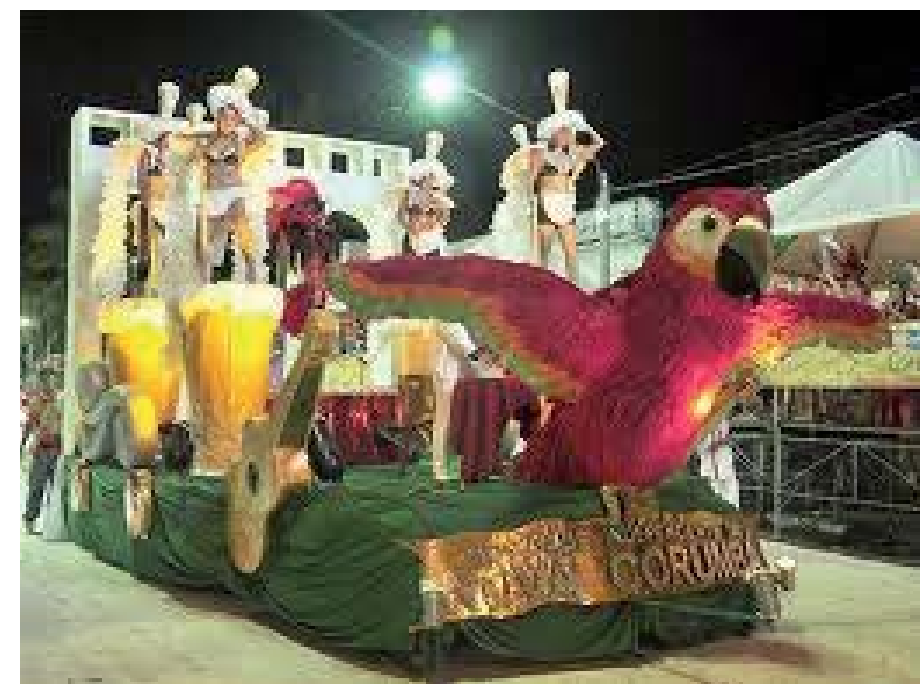

Figura 1 - Carro alegórico Abre-Alas

Fonte: Pantanal News (ANACHE, 2014).

O adereço do cavalo pantaneiro, apresentado no desfile da escola de samba, anunciou a sua celebração. E a história de seu surgimento, a partir dos cavalos ibéricos, trazidos pelos peões espanhóis, que tiveram que se adaptar às condições adversas do Pantanal, foi exposta na Primeira Ala das baianas.

O primeiro casal de Mestre-Sala e Porta-Bandeiras apresentou-se como o toureiro e a bailarina, cujo tecido das fantasias foi ornamentado com pedrarias, apliques, paetês, strass e plumas, para dar ênfase ao ponto alto da comemoração das touradas, juntamente com as festas e noites espanholas. Esses sentidos e efeitos foram produzidos ou expressos na Terceira Ala, Segunda Alegoria e nos Destaques de chão.

Nessa primeira fase do desfile, a bateria "Soldado Guaicuru" da escola de samba (figura 2) apresentou-se com 120 componentes, trajando, como alegoria, o uniforme do soldado e o cocar do índio Guaicuru, símbolos do batalhão de índios e soldados, montados nos cavalos pantaneiros. A alegoria figurativizava aqueles que lutaram, junto com os brasileiros, na Guerra do Paraguai. 


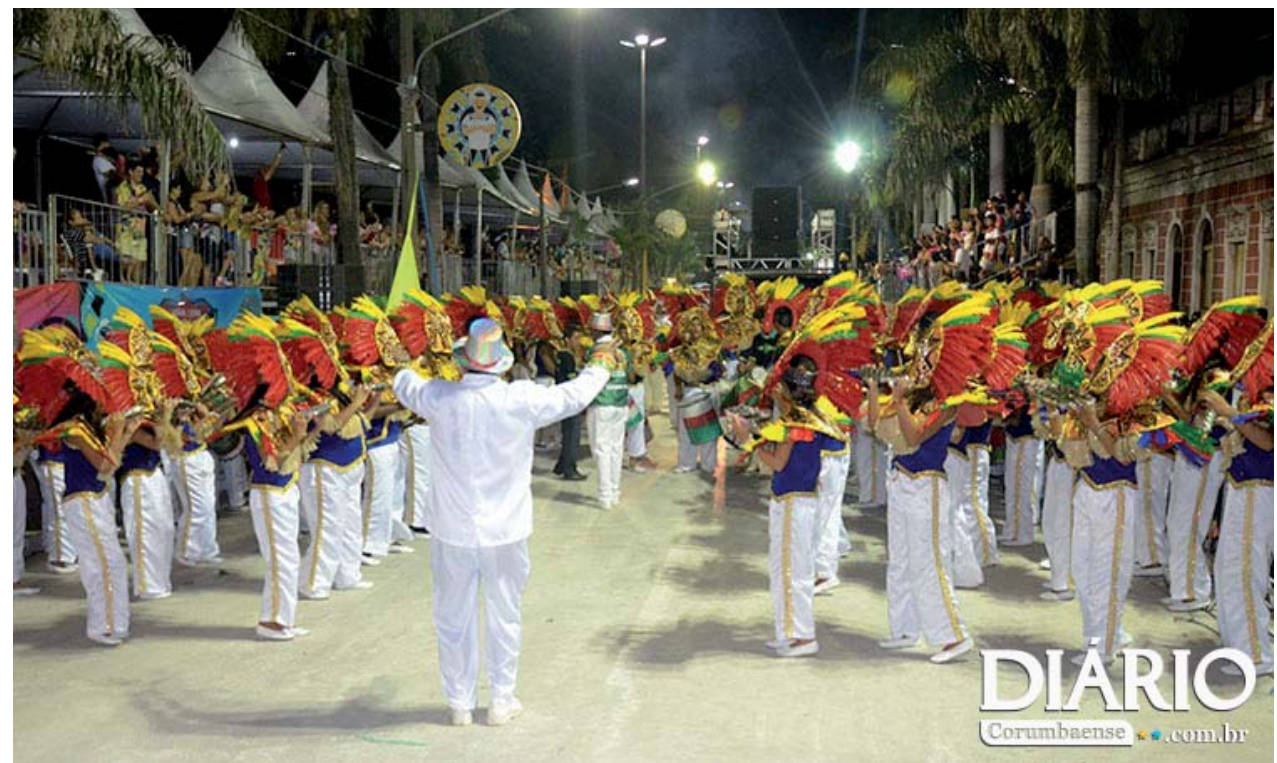

Figura 2 - Bateria Soldado Guaicuru

Fonte: Diário Corumbaense (2014)

A Quarta Ala acenou para a riqueza espanhola, por meio das cores branco, amarelo e dourado, e a busca do ouro que os espanhóis pensavam existir na região do pantanal.

No segundo setor do desfile - "Índios Guaicurus", apresentados na Quinta Ala -, a escola homenageou os primeiros índios, Kadiwéus Guaicuru, que domesticaram o cavalo na região do pantanal, já que as outras etnias, por acharem que o cavalo era um animal feroz, o matavam.

Em direção à Sexta Ala, com símbolos dourados e amarelos, representaram o comércio entre as etnias locais e os índios dos Andes, façanha localizada na estrada que cruza a região do pantanal, denominada "A Trilha dos Incas", existente até hoje.

A Sétima Ala importou os guardiões, com fantasias ilustradas com pele de onça e pena de pato verde, que faziam a guarda não só das tribos como também das suas riquezas. O mar que os espanhóis acreditavam existir no Pantanal foi apresentado pela figura do segundo casal de Mestre-Sala e Porta-Bandeiras, com a fantasia "Mar de Xaraes", confeccionada em tecido organza cristal, nas cores azul, prata e branco. Logo após, a Terceira Alegoria retratou as riquezas das cerâmicas indígenas e da nossa pesca.

O terceiro setor do desfile - "O Pantanal e a criação da Nhecolândia" - discorreu, na Oitava Ala, sobre a fauna e flora da região e as etnias existentes na Nhecolândia.
Já na Nona e Décima Alas, enalteceu-se o pescador pantaneiro que caçava para a subsistência. Momento em que comparece a Musa da Escola e Passista, trajando a fantasia "Pôr do Sol Pantaneiro", composta por calça branca, camisa laranja e chapéu de vaqueiro. E, no final desse setor, manifestou-se a Quarta Alegoria, denominada "A Nhecolândia e o Cavalo Pantaneiro".

"O Cavalo Pantaneiro e a viagem 'Rota Pantaneira, Cavalgando pelo Pantanal'" compuseram o quarto e último setor do desfile. Nesse momento, narrou-se, na passarela do samba, a resistência do cavalo pantaneiro e sua lida na região do pantanal: em época de enchentes, $\mathrm{o}$ animal mergulha para se alimentar no pasto submerso na água e o seu casco não amolece no contato com a água. Esse fato foi constituído na Décima Primeira Ala.

Na Décima Segunda Ala, foram celebradas as figuras do Guaicuru Tropeiro e do Vaqueiro Pantaneiro, nas cores branco e bronze ferrugem. A relação, na lida diária, dos Vaqueiros e Guaicurus, montados nos cavalos pantaneiros, fez-se presente na Décima Terceira Ala.

Para a representação das tarefas cotidianas dos Vaqueiros, foram expostos, como Quinta Alegoria, o carro de boi, o acampamento boiadeiro e as suas tralhas.

Finalizando e celebrando o desfile, na Décima Quarta Ala, desfilou a velha guarda, 
composta de aproximadamente 40 integrantes entusiasmados, com uma rosa vermelha em uma das mãos e, na outra, um chapéu branco. Em suas fantasias, calça verde, camiseta vermelha e cinto branco, numa homenagem às cores da escola de samba. Nesse momento, celebrou-se a história contada por Luiz Otávio Carneiro (Figura 3), tetraneto de Joaquim Eugênio, afetuosamente lembrado como Nheco Gomes da Silva, o valente desbravador e órfão do Barão de Vila Maria (ALBANEZE, 2014).

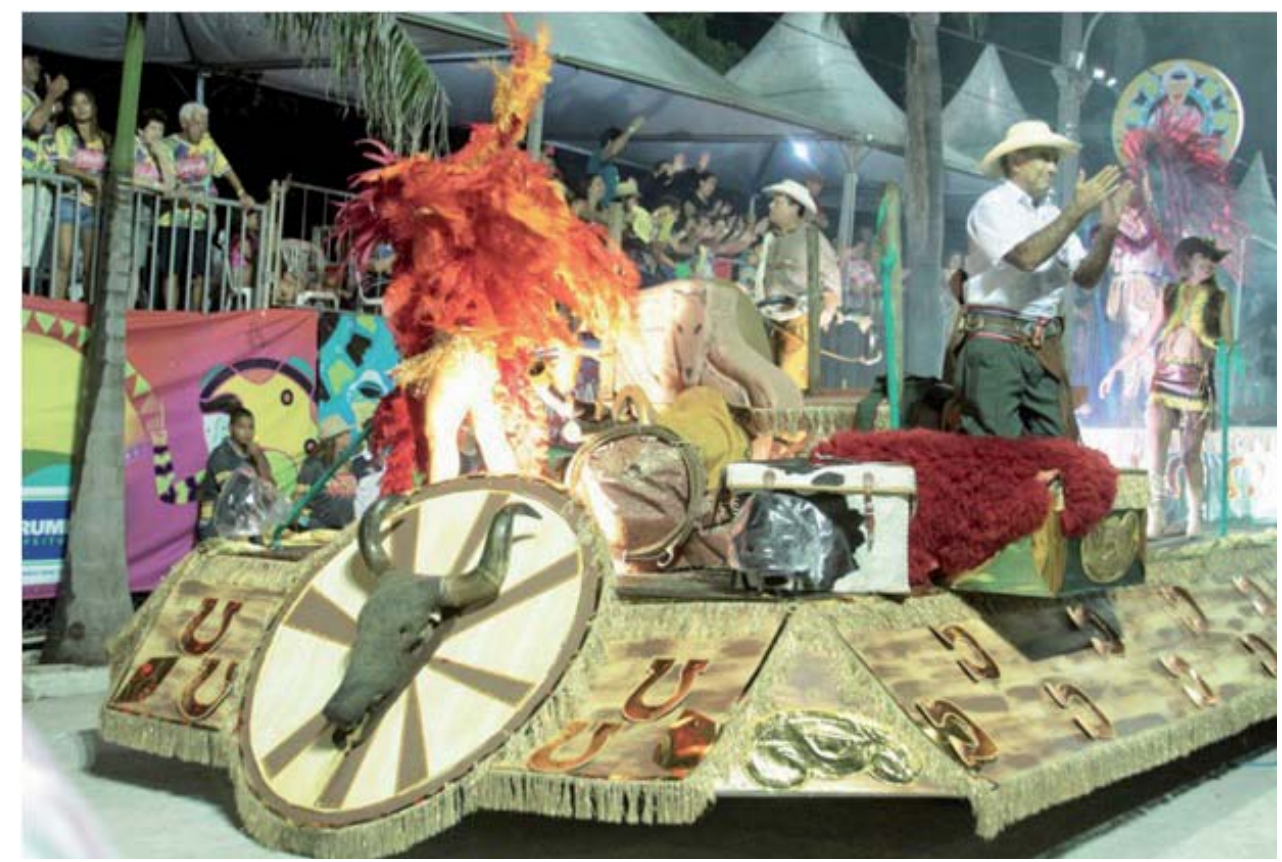

Figura 3 - Carro alegórico Luiz Otavio Carneiro, símbolo do vaqueiro Fonte: Pantanal News (2014)

\section{CONSIDERAÇÕES FINAIS}

A festa popular "Carnaval de Corumbá", como processo material e simbólico, tem trazido à tona, nesse município sul-mato-grossense, ao longo dos anos, relações entre comunidades e valores históricos e sociais, garantindo, assim, o caráter ideológico dessa antiga manifestação cultural.

Nesse contexto, divulgando o potencial turístico e aumentando a geração de renda local, a Escola de Samba Mocidade Independente da Nova Corumbá celebrou, no ano de 2014, a história de ocupação e colonização da região de Corumbá, com ênfase no Cavalo Pantaneiro, importante referência para o desenvolvimento regional.

Estabelecendo articulação direta entre o passado e o presente (para evocar as palavras de Queiroz, 1973), no espaço-cenário produzido pela Mocidade Independente da Nova Corumbá, feitos e seres adquiriram sentido, assumindo contornos de fenômeno estético, evidenciando que, em decorrência do caráter dinâmico da cultura, sempre são possíveis os movimentos de reapropriação e ressignificação da História.

\section{REFERÊNCIAS}

ALBANEZE, G. Entrevista sobre a Escola de Samba Mocidade Independente da Nova Corumbá. Entrevistadora: Denise Abrão Nachif. Corumbá, MS: Hotel Nacional, 9 out. 2014.

ALVES, G. L. Educação nos campos de pecuária do Pantanal da Nhecolândia. In: SEMINÁRIO NACIONAL DE ESTUDOS E PESQUISAS “HISTÓRIA, SOCIEDADE E EDUCAÇÃO NO BRASIL", 9., 31/07 a 03/08/2012. Anais eletrônicos... João Pessoa, PB: Universidade Federal da Paraíba, 2012.

. Pantanal da Nhecolândia e modernização tecnológica. Campo Grande, MS: Editora UFMS, 2004.

ANACHE, Luiz Mario. Festa da Mocidade da Nova Corumbá acontece nesta sexta feira. Pantanal News, Corumbá, 18 fev. 2014. Disponível em: <http:/ / www. pantanalnews.com.br/contents.php?CID=97271>. Acesso em: 27 jun. 2015. 
ARAUJO, H. Carnaval: seis milênios de história. Rio de Janeiro, RJ: Gryphus, 2003.

BARBOSA, F. M. As dimensões teóricas do evento. 2004. Dissertação (Mestrado em Hospitalidade) Universidade Anhembi-Morumbi, São Paulo, SP.

BARROS, A. L. Gente pantaneira: crônicas da sua história. Rio de Janeiro: Lacerda Editores, 1998.

CANCLINI, N. G. Culturas híbridas: estratégias para entrar e sair da modernidade. São Paulo: EDUSP, 2011.

CARNEIRO, M. A. Forte Coimbra. Corumbá, MS: Edição do autor, 2014.

COM muito brilho e luxo, Nova Corumbá mostra saga do cavalo pantaneiro. Pérola News, Ladário, 04 mar. 2014. Disponível em: <http://perolanews.com.br/noticias/corumba/com-muito-brilho-e-luxo-nova-corumba-mostra-saga-do-cavalo-pantaneiro\#>. Acesso em: 27 jun. 2015.

DIAS, F. H. A (Re)territorialização do patrimônio cultural tombado do Porto Geral de Corumbá-MS no contexto do desenvolvimento local. Campo Grande, MS: Edição do autor, 2009.

FERNANDES, Marcelo. Mocidade supera problemas e levanta o público na passarela do samba.
Diário Corumbaense, Corumbá, 04 mar. 2014. Disponível em: <http://www.diarionline.com.br/?s= noticia\&id=66645> . Acesso em: 27 jun. 2015.

FERNANDES, C. Movimentos urbanos e o Rio Paraguai. Campo Grande, MS: Alvorada, 2009.

PROENÇA, A. C. Corumbá de todas as Graças. Campo Grande, MS: Edição do autor, 1992a.

Pantanal - gente, tradição e história. 2. ed. Campo Grande, MS: Edição do autor, 1992b.

QUEIROZ, M. I. P. O campesinato brasileiro. Petrópolis, RJ: Vozes; São Paulo: EDUSP, 1973.

Carnaval brasileiro: o vivido e o mito. São Paulo: Brasiliense, 1999.

SANTOS, M. A natureza do espaço. Técnica e tempo, razão e emoção. São Paulo: Hucitec, 1996.

SOUZA, J. C. O caráter religioso e profano das festas populares: Corumbá, passagem do século XIX para o XX. Revista Brasileira de História, São Paulo, v. 24, n. 48, p. 331-351, 2004.

SOUZA, L. G. História de Corumbá. [S.l.]: Edição do autor, [s.d.]. 